Проценко А. Е., Малышева Д. П., Петров В. В., Шпилев А. М.

ИССЛЕДОВАНИЕ ВЛИЯНИЯ ТЕРМИЧЕСКОЙ ОБРАБОТКИ НА ФИЗИКО-МЕХАНИЧЕСКИЕ СВОЙСТВА СЭНДВИЧ-КОНСТРУКЦИЙ

Проценко А. Е., Малышева Д. П., Петров В. В., Шпилев А. М.

A. E. Protsenko, D. P. Malysheva, V. V. Petrov, A. M. Shpilev

ИССЛЕДОВАНИЕ ВЛИЯНИЯ ТЕРМИЧЕСКОЙ ОБРАБОТКИ

НА ФИЗИКО-МЕХАНИЧЕСКИЕ СВОЙСТВА СЭНДВИЧ-КОНСТРУКЦИЙ

\title{
STUDY OF THE EFFECT OF THERMAL TREATMENT \\ ON PHYSICAL AND MECHANICAL PROPERTIES OF SANDWICH STRUCTURES
}

Проценко Александр Евгеньевич - кандидат технических наук, доцент кафедры технологии переработки нефти и полимеров Комсомольского-на-Амуре государственного университета (Россия, Комсомольск-наАмуре); 681013, Хабаровский край, г. Комсомольск-на-Амуре, пр. Ленина, $27 . \quad$ Е-таil: protsenko.ae@yandex.ru.

Mr. Alexander E. Protsenko - PhD in Engineering, Assistant Professor, Department of Technology of oil and polymer processing, Komsomolsk-on-Amur State University (Russia, Komsomolsk-on-Amur); 681013, Khabarovsk territory, Komsomolsk-on-Amur, 27 Lenin str. E-mail: protsenko.ae@yandex.ru.

Малышева Дарья Павловна - аспирант кафедры технологии самолётостроения Комсомольского-наАмуре государственного университета (Россия, Комсомольск-на-Амуре); 681013, Хабаровский край, г. Комсомольск-на-Амуре, пр. Ленина, 27. E-mail: daryareshet@,mail.ru.

Ms. Daria P. Malysheva - a post-graduate student, Department of airplane technology, Komsomolsk-on-Amur State University (Russia, Komsomolsk-on-Amur); 681013, Khabarovsk territory, Komsomolsk-on-Amur, 27 Lenin str. E-mail: daryareshet@mail.ru.

Петров Виктор Викторович - доктор технических наук, профессор кафедры технологии переработки нефти и полимеров Комсомольского-на-Амуре государственного университета (Россия, Комсомольск-наАмуре); 681013, Хабаровский край, г. Комсомольск-на-Амуре, пр. Ленина, 27. E-mail: petrovpng@mail.ru.

Mr. Victor V. Petrov - Dr.hab. of Engineering, Professor, Department of Technology of oil and polymer processing, Komsomolsk-on-Amur State University (Russia, Komsomolsk-on-Amur); 681013, Khabarovsk territory, Komsomolsk-on-Amur, 27 Lenin str. E-mail: petrovpng@mail.ru.

Шпилев Анатолий Михайлович - доктор технических наук, профессор Комсомольского-на-Амуре государственного университета (Россия, Комсомольск-на-Амуре); 681013, Хабаровский край, г. Комсомольскна-Амуре, пр. Ленина, 27. E-mail: Shpilev@knastu.ru.

Mr. Anatoly M. Shpilev - Dr.hab. of Engineering, Professor, Komsomolsk-on-Amur State University (Russia, Komsomolsk-on-Amur); 681013, Khabarovsk territory, Komsomolsk-on-Amur, 27 Lenin str. E-mail: Shpilev@knastu.ru.

Аннотация. В статье представлены данные экспериментального исследования влияния термической обработки на физико-механические свойства сэндвич-конструкций. Сэндвич-конструкции были получены с использованием метода VaRTM. Термическая обработка проводилась при значениях температуры, равных $80{ }^{\circ} \mathrm{C}$ и $60{ }^{\circ} \mathrm{C}$ при различном времени выдержки. Были проведены испытания разрушающего контроля сэндвич-конструкций и стеклопластиков. Полученные данные коррелируют с результатами исследований степени набухания отверждённых связующих. Исследования структуры стеклопластиков показывают, что при термообработке происходит трансформация надмолекулярной структуры полимерной матрицы.

Summary. The article presents the data of an experimental study heat treatment influence on the physical and mechanical properties of cured samples of sandwich structures. The sandwich structures were made using VaRTM method. Heat treatment at $80{ }^{\circ} \mathrm{C}$ and $60{ }^{\circ} \mathrm{C}$ leads to increase in the bending strength. The tests of destructive control of sandwich structures and fiberglass plastics have been carried out. The SEM micrographs of the microstrustructures of fiberglass reinforced plastic samples show that during heat treatment there is a structural refinement of the polymer matrix. The results correlate with the data of swelling of the cured binder.

Ключевые слова: сэндвич-конструкции, полимерный композиционный материал, прочность, набухание, сканирующая электронная микроскопия, эпоксивинилэфирное связующее, термическая обработка. 
Key words: sandwich structures, polymer composite material, strength, swelling, scanning electron microscopy, epoxy vinyl ester binder, heat treatment.

УДК 678.5.046

\section{Введение}

Полимерные композиционные материалы (ПКМ) на основе термореактивных связующих широко используются в различных отраслях. Это связано с их низкой плотностью по сравнению с металлами, высокой прочностью в направлении армирования, высокой коррозионной стойкостью, а также низкими эксплуатационными расходами этих конструкций и изделий из таких материалов.

Около 80 \% современных пассажирских самолётов выполнены из трёхслойных сотовых панелей из-за их относительно высокой удельной прочности и жёсткости по сравнению с традиционными монолитными конструкциями. Технология изготовления ускоренного формования сэндвич-панелей сочетает в себе преимущества вакуума и прессования [1].

Сэндвич-конструкции широко используются в судостроительной промышленности. В авиаконструкциях эти материалы позволяют уменьшить вес конструкций, а также увеличить плавучесть $[3,4]$.

В публикациях [5; 6] рассматривается инженерная технология конструкций из полимерных композиционных материалов, которые успешно применяются при строительстве современных судов.

При изготовлении крупногабаритных конструкций из панелей среднего слоя наиболее оптимальными являются безавтоклавные методы - вакуумная инфузия (VaRTM) для изделий нестандартной конфигурации и малой серии и инжекционный метод низкого давления (light-RTM) для типовых изделий [2]. Важную роль при использовании этих методов играют технологические параметры: время жизни связующего, температура окружающей среды, время выдержки под вакуумом, а также время и температура постотверждения.

\section{Методика исследования}

Исследование проводилось на панелях среднего слоя, представляющих гофрированный элемент, образованный пенопластовыми вкладышами (см. рис.1). Гофрированный элемент выполнен из стеклопластика на основе трёх слоёв полотняной ткани Ст-62004 (ХКК Композит) с нулевым углом армирования и эпоксивинилэфирного не предускоренного связующего Dion 9300 FR (Reich Hold). Формообразующие вкладыши изготавливались из поливинилхлоридного пенопласта Divinycell Н35 высотой 40 мм.

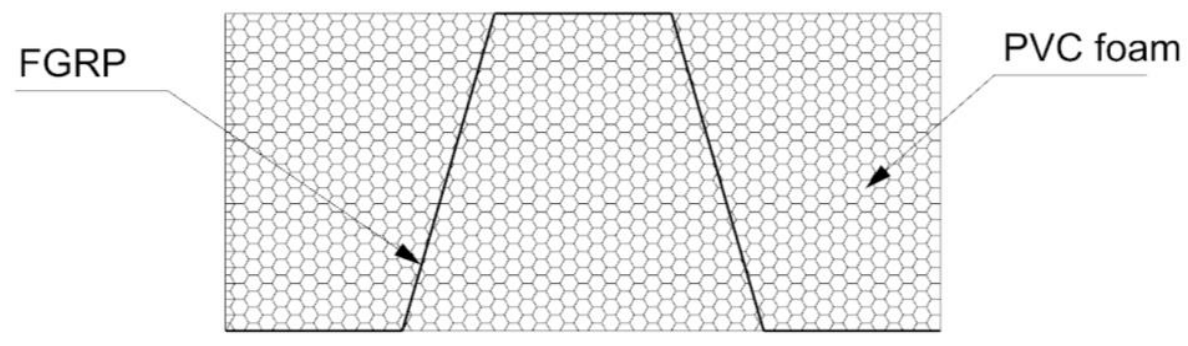

Рис. 1. Образец среднего слоя

Все образцы получали методом вакуумной инфузии. Связующее изготавливалось из четыpёх компонентов по рецептуре: Dion 9300 FR - 100 масс. ч., Accelerator NORPOL 9802 - 3 масс. ч., Peroxide NORPOL № 11 - 2 масс. ч., Inhibitor NORPOL 9854 - 0,01 масс. ч. Время жизни смеси при нормальных условиях составляет 120 - 150 минут.

Отверждение стеклопластика проводилось в вакууме (0,01 МПа) при комнатной температуре в течение 6 часов. Выдержка изделия при комнатной температуре с целью достижения полной 
Проценко А. Е., Малышева Д. П., Петров В. В., Шпилев А. М.

ИССЛЕДОВАНИЕ ВЛИЯНИЯ ТЕРМИЧЕСКОЙ ОБРАБОТКИ НА ФИЗИКО-МЕХАНИЧЕСКИЕ СВОЙСТВА СЭНДВИЧ-КОНСТРУКЦИЙ

полимеризации образцов проводилась в течение 10 дней. В дальнейшем образцы подвергались термической обработке при $60{ }^{\circ} \mathrm{C}$ в течение $5,10,15$ часов и при $80{ }^{\circ} \mathrm{C}$ в течение $4,8,12$ часов.

Для исследования структуры эпоксивинилэфирных связующих методом набухания использовались отверждённые образцы толщиной 10 мм и 10 мм в диаметре.

Начальную массу $\left(m_{0}\right)$ определяли на аналитических весах. Один образец использовали как контрольный, а другие образцы подвергали термообработке в сушильном шкафу при $80{ }^{\circ} \mathrm{C}$.

По завершении термообработки все образцы погружали в растворитель, состоящий из ацетона $33 \%$, циклогексанона $33 \%$ и толуола $34 \%$. Через 24 часа образцы вынимали, остаточный растворитель удаляли фильтровальной бумагой, после чего их взвешивали для определения массы набухшего образца $(m)$. Измерения продолжались до тех пор, пока масса не перестала изменяться.

Степень набухания $(\alpha)$ для каждого образца рассчитывается согласно формуле

$$
\alpha=\frac{m-m_{0}}{m_{0}} \times 100 \%
$$

где $\alpha$ - степень набухания; $m$ - масса набухшего образца; $m_{0}$ - начальная масса.

Механические испытания проводились на испытательной машине INSTRON 3382, твёрдость исследовалась по методу Бринелля на приборе TIME Group Inc. TH600.

\section{Результаты исследования}

Из полученных экспериментальных данных следует, что термическая обработка приводит к увеличению несущей способности сэндвич-конструкций (см. рис. 2). При термообработке образцов при температуре $60{ }^{\circ} \mathrm{C}$ нагрузка, приводящая к разрушению образца, линейно возрастает на 14 \% при пятичасовой выдержке и повышается на 27 \% при пятнадцатичасовой. Термообработка при $80{ }^{\circ} \mathrm{C}$ в течение 4 часов способствует резкому увеличению несущей нагрузки сэндвичконструкции на 30,7 \%, дальнейшая обработка при этой температуре приводит к незначительному увеличению предела прочности - на 34,8 \%.

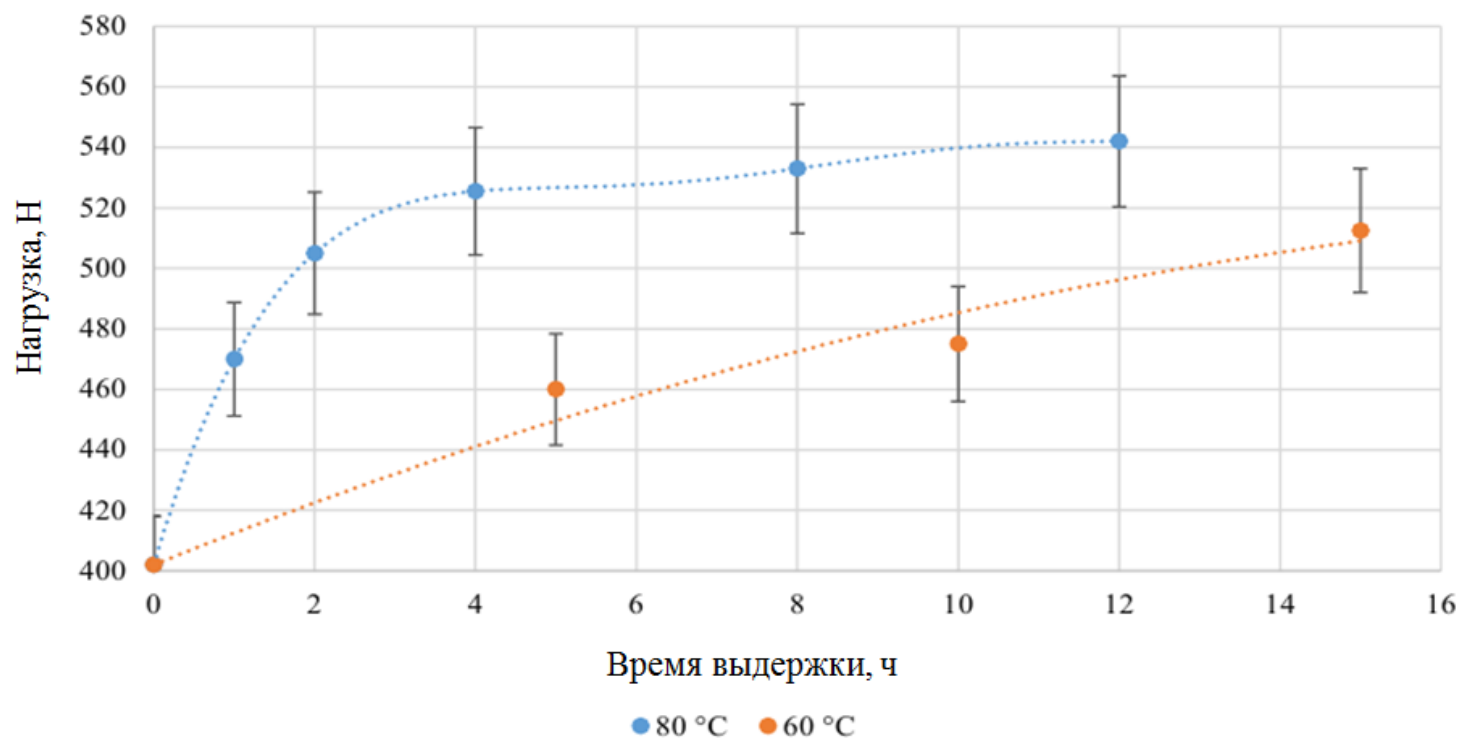

Рис. 2. Зависимость предельной нагрузки от времени и температуры выдержки

По данным визуального контроля излома образцов (см. рис. 3) следует, что образцы без термообработки при трёхточечном изгибе разрушаются по краю адгезионного слоя пенопластстеклопластик, что свидетельствует о недостаточной прочности клеевого соединения на границе между пенопластовым заполнителем и стеклотканью гофрированного слоя. Разрушение термообработанных образцов происходит по пенопластовому заполнителю. Это показывает, что при тер- 


\section{Учёные записки \\ Комсомольского-на-Амуре государственного технического университета \\ No) \\ 2019}

мообработке происходит упрочнение клеевого слоя за счёт протекания окончательного отверждения эпоксивинилэфирного связующего при повышенных температурах.

a)

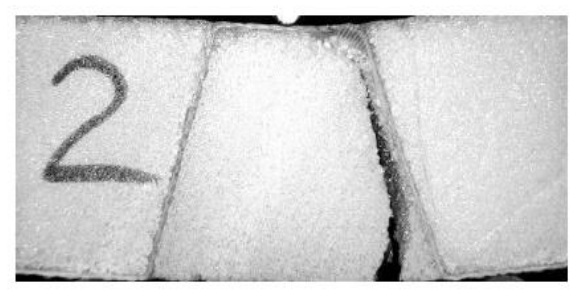

б)

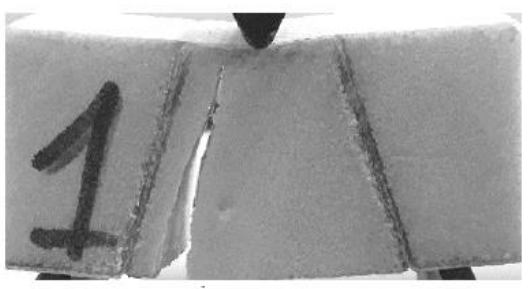

B)

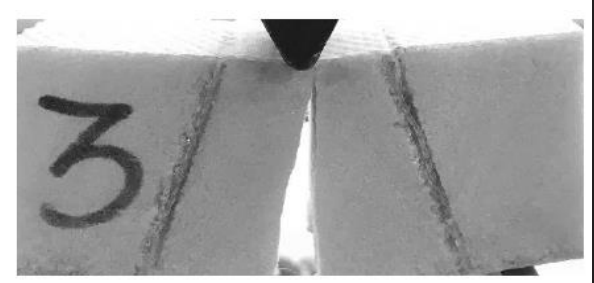

Рис. 3. Фотографии испытанных образцов при разном времени экспозиции:

a - без термообработки; при термообработке $\left(80^{\circ} \mathrm{C}\right)$ :

б - при 2-часовой выдержке; в - при 4-часовой выдержке

В то же время были проведены испытания стеклопластиков, полученных вакууминфузионным методом, что и сэндвич-конструкции. Данные механических испытаний представлены в табл. 1.

Таблица 1

Механические испытания стеклопластиков

\begin{tabular}{|l|c|c|c|}
\hline \multicolumn{1}{|c|}{ Образец } & Твёрдость, НВ & Изгиб, $\sigma_{b}[\mathrm{MПа]}$ & $\begin{array}{c}\text { Предел прочности, } \sigma_{t} \\
{[\mathrm{MПа]}}\end{array}$ \\
\hline Стеклопластик & 44,6 & 487,9 & 467,9 \\
\hline $\begin{array}{l}\text { Термообработанный } \\
\text { стеклопластик }\end{array}$ & 48,1 & 831,9 & 831,9 \\
\hline
\end{tabular}

Таким образом, результаты проведённых испытаний показывают, что термообработка стеклопластика приводит к значительному увеличению его механических характеристик.

Представленные данные были также подтверждены исследованием набухания термообработанных образцов (см. рис 4).

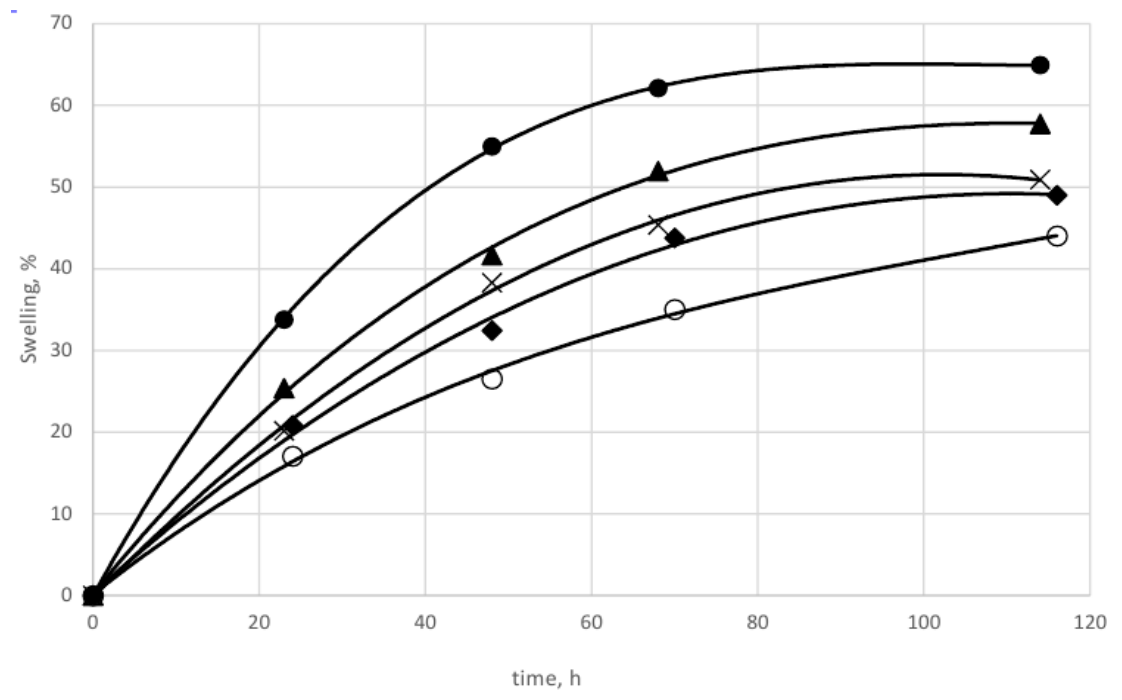

Рис. 4. Влияние термообработки на набухание 
Проценко А. Е., Малышева Д. П., Петров В. В., Шпилев А. М.

ИССЛЕДОВАНИЕ ВЛИЯНИЯ ТЕРМИЧЕСКОЙ ОБРАБОТКИ НА ФИЗИКО-МЕХАНИЧЕСКИЕ СВОЙСТВА СЭНДВИЧ-КОНСТРУКЦИЙ

В результате термообработки степень набухания уменьшается на 7 \%, а при 4-часовой выдержке этот параметр уменьшается на 14 \%. Восьмичасовая и двенадцатичасовая выдержка для образцов приводит к снижению набухания на $16 \%$ и $21 \%$ соответственно. Полученные данные указывают на процесс постотверждения, протекающий при высокой температуре и приводящий к увеличению количества поперечных связей в полимере. Это препятствует проникновению молекул растворителя внутри трёхмерной решётчатой структуры отверждённой макромолекулы.

Фрактограммы образцов стеклопластика, представленные на рис. 5, показывают, что в процессе термической обработки происходит измельчение структуры полимерной матрицы, приводящее к закономерному уменьшению толщины ламелей вследствие протекания процессов сшивки при выдержке полимеров в условиях повышенной температуры.

a)

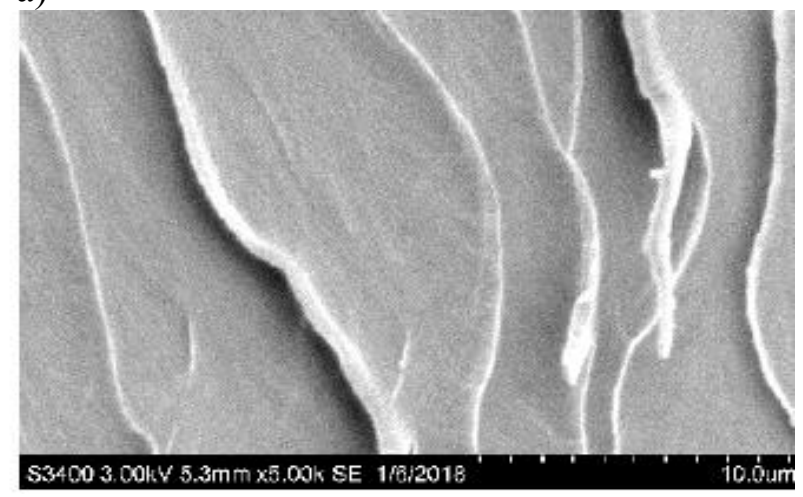

б)

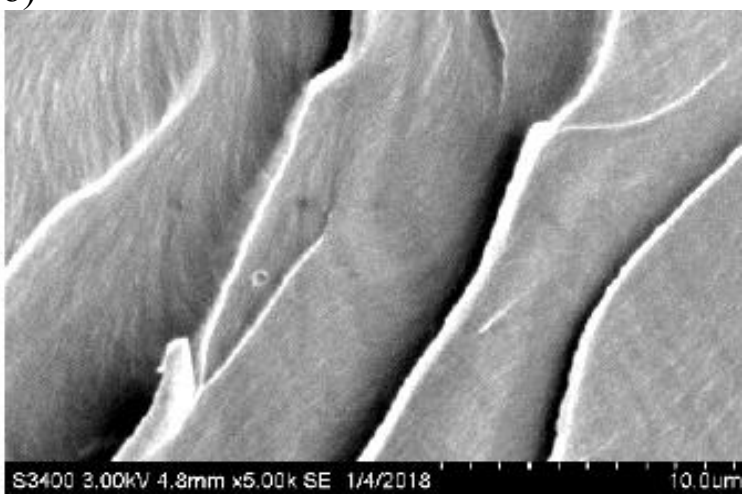

B)

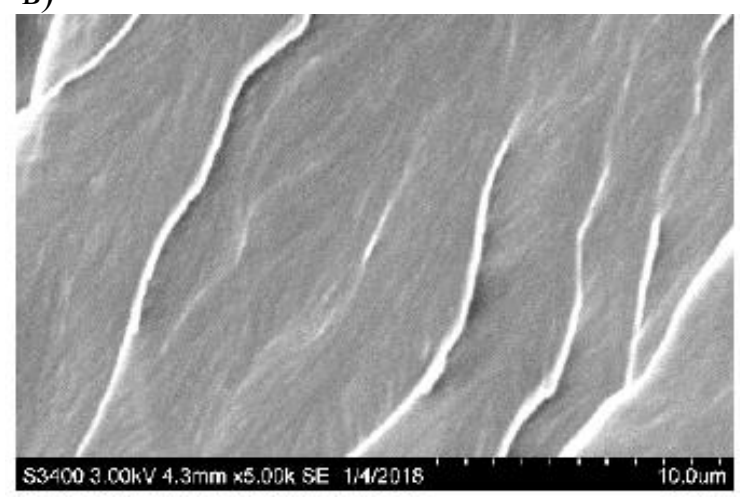

Рис. 5. Структура стеклопластиков:

$\mathrm{a}$ - без термообработки; при термообработке $\left(80^{\circ} \mathrm{C}\right)$ : б - при 4-часовой выдержке; в - при 8-часовой выдержке

\section{Заключение}

1. Термообработка ПКМ является обязательной технологической операцией, обеспечивающей повышение прочности за счёт протекания процессов постотверждения эпоксивинилэфирного связующего. По данным экспериментальных исследований, оптимальной является обработка композиционного материала при температуре $80{ }^{\circ} \mathrm{C}$ в течение 4 часов. Максимальное напряжение при изгибе термообработанного стеклопластика увеличилось на 76 \%, а максимальное напряжение при растяжении - на $78 \%$.

2. В процессе термической обработки ПКМ происходит измельчение структуры полимерной матрицы, приводящее к закономерному уменьшению толщины ламелей вследствие протекания процессов сшивки при выдержке полимеров в условиях повышенной температуры.

3. Степень набухания ПКМ закономерно снижается пропорционально времени термообработки, что также является следствием увеличения числа поперечных связей в полимерной матрице. 


\section{ЛИТЕРАТУРА}

1. Технология ускоренного формования трёхслойных сотовых панелей интерьера самолёта / Е. А. Вешкин, В. И. Постнов, О. Б. Застрогина, Р. А. Сатдинов / Известия Самарского научного центра Российской академии наук. - 2013. - Т. 15. - № 44.

2. Булкин, В. А. Применение перспективных композиционных материалов в надводном судостроении В. А. Булкин, Н. Н. Федонюк, А. В. Шляхтенко. - Морской вестник. - 2013. - № 1. - С. 7-8.

3. Gullberg, O. Design and construction of GRP sandwich ship hulls. Marine Struct / O. Gullberg, K. A. Olsson. 1990. - Vol. 3(2). - P. 93-109.

4. Karthikeyan, C. S. Investigation of bending modulus of fiber-reinforced syntactic foams for sandwich and structural applications. Polym. Adv. Tech / C. S. Karthikeyan, S. Sankaran. - 2007. - Vol. - 18(3). - P. $254-256$.

5. Appolonov, E. M. Polymeric composite materials. Innovations in the industry, Innovations / E. M. Appolonov, N. N. Fedonyuk, V. M. Shaposhnikov. - 2013. - Vol. 181. - P. 18-20.

6. Mouritz, A. P. et al. Review of advanced composite structures for naval ships and submarines. Comp. Struct / A. P. Mouritz. - 2001. - Vol. 53(1). - P. 21-42. 